\title{
EVALUATION OF RGB-BASED VEGETATION INDICES FROM UAV IMAGERY TO ESTIMATE FORAGE YIELD IN GRASSLAND
}

\author{
U. Lussem ${ }^{1 *}$, A. Bolten ${ }^{1}$, M. L. Gnyp ${ }^{2}$, J. Jasper ${ }^{2}$, G. Bareth ${ }^{1,3}$ \\ ${ }^{1}$ Institute of Geography, GIS \& Remote Sensing Group, University of Cologne, Albertus-Magnus-Platz, 50923 Cologne, Germany - \\ (ulrike.lussem, a.bolten, g.bareth)@uni-koeln.de \\ ${ }^{2}$ Research Center for Crop Nutrition Hanninghof, Yara International ASA, 48249 Dülmen, Germany - (martin.gnyp, \\ joerg.jasper)@yara.com \\ ${ }^{3}$ ZFL - Center for Remote Sensing of Land Surfaces, University of Bonn, Genscherallee 3, 53113 Bonn, Germany
}

\section{WG III/10}

KEY WORDS: RGB, vegetation indices, unmanned aerial vehicle, biomass, yield, grassland, pasture

\begin{abstract}
:
Monitoring forage yield throughout the growing season is of key importance to support management decisions on grasslands/pastures. Especially on intensely managed grasslands, where nitrogen fertilizer and/or manure are applied regularly, precision agriculture applications are beneficial to support sustainable, site-specific management decisions on fertilizer treatment, grazing management and yield forecasting to mitigate potential negative impacts. To support these management decisions, timely and accurate information is needed on plant parameters (e.g. forage yield) with a high spatial and temporal resolution. However, in highly heterogeneous plant communities such as grasslands, assessing their in-field variability non-destructively to determine e.g. adequate fertilizer application still remains challenging. Especially biomass/yield estimation, as an important parameter in assessing grassland quality and quantity, is rather laborious. Forage yield (dry or fresh matter) is mostly measured manually with rising plate meters (RPM) or ultrasonic sensors (handheld or mounted on vehicles). Thus the in-field variability cannot be assessed for the entire field or only with potential disturbances. Using unmanned aerial vehicles (UAV) equipped with consumer grade RGB cameras in-field variability can be assessed by computing RGB-based vegetation indices. In this contribution we want to test and evaluate the robustness of RGB-based vegetation indices to estimate dry matter forage yield on a recently established experimental grassland site in Germany. Furthermore, the RGBbased VIs are compared to indices computed from the Yara N-Sensor. The results show a good correlation of forage yield with RGBbased VIs such as the NGRDI with $\mathrm{R}^{2}$ values of 0.62 .
\end{abstract}

\section{INTRODUCTION}

Grasslands are of global importance for providing ecosystem functions and services. Managed grasslands cover about twice the area of land under cultivation for arable crops (Ellis \& Ramankutty 2008). Monitoring forage yield is of primary concern in managed grasslands for grazing, hay and silage production or biofuel production. Information on biomass and its spatial distribution within fields in high temporal and spatial resolution is an important step towards yield optimisation and nutrient balancing/budgeting as means of precision agriculture (PA) (Schellberg \& Verbruggen, 2014). However, commonly applied manual measurement techniques of standing biomass such as clipping, disc or rising plate meters, or spectroradiometer measurements do not meet the requirements of a high resolution assessment of the in-field heterogeneity of standing biomass (Schellberg \& Verbruggen, 2014). Analysing information of RGB images from consumer grade cameras mounted on unmanned aerial vehicles (UAV) can offer a cost efficient and near-real time assessment of forage yield with high temporal and spatial resolution (Hunt et al 2013).

Vegetation indices derived from aerial RGB images to predict biomass in crops have been investigated in only a few studies (e.g. Bendig et al. 2015, Hunt et al. 2005, Jannoura et al. 2015). In this study selected RGB-based vegetation indices are tested to predict dry matter yield and compared to three indices from the visible to near-infrared domain calculated from spectroradiometer measurements (Yara N-Sensor).

\section{STUDY AREA}

The study area is located south-east of the city of Cologne in Neunkirchen-Seelscheid (Bergisches Land region).

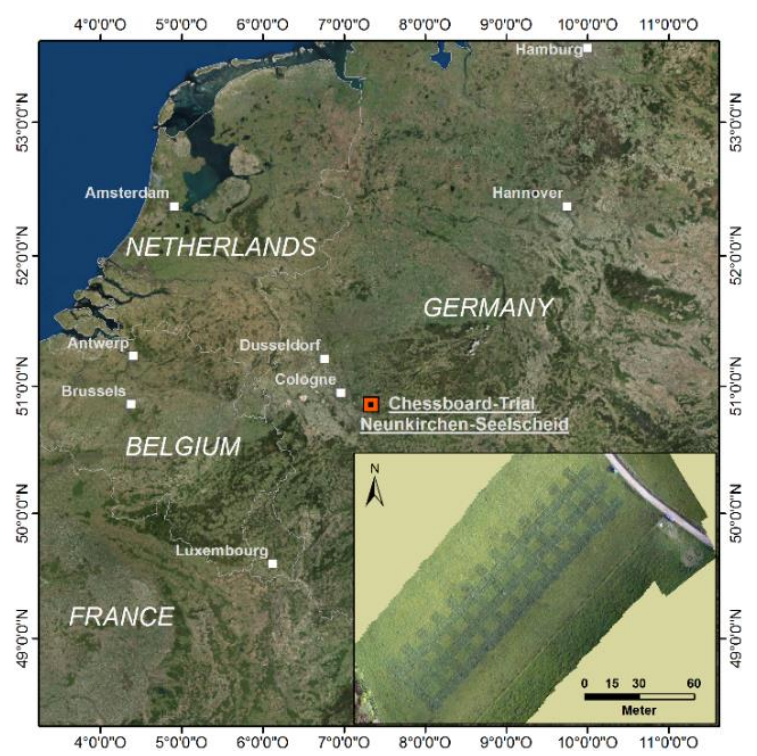

Figure 1. Location of Chessboard field trial in Germany (data source: ESRI-Basemaps, Eurostat). Inset map: Orthomosaic of test site (A. Bolten). 
The investigated field trial was established in 2017 on a conventionally managed permanent grassland field from a local farmer. The field has a variability in soil and topography (steady slope with northeast to southwest inclination and $25 \mathrm{~m}$ difference in height).

The four fertilizer treatments $\left(0,50,100,150 \mathrm{~kg} \mathrm{~N} \mathrm{ha}^{-1}\right)$ are applied in a chessboard-like pattern with 39 replicates per treatment resulting in 156 plots with an area of $36 \mathrm{~m}^{2}$ each. The cutting regime was kept according to the local pattern of three cuts per growing season (April-May, May-July, and JulyOctober).

\section{MATERIALS AND METHODS}

\subsection{Data acquisition}

For this contribution we will focus on the second cut in 2017 ( $28^{\text {th }}$ of July). Biomass samples of the grass sward in all 156 plots were taken from $2.6 \mathrm{~m}^{2}$ of each plot with an electric mower. The fresh samples were weighed and a subsample was taken for drying to determine dry matter yield in tonnes per hectare $\left(\mathrm{DM} \mathrm{tha}{ }^{-1}\right)$.

One day in advance of the biomass sampling UAV-flights and spectral measurements were carried out. Spectral measurements were executed with the handheld device of the Yara N-Sensor (Yara International ASA, Oslo, Norway) (spectral range of 400 $1000 \mathrm{~nm}$ with $10 \mathrm{~nm}$ spectral resolution) at a $60^{\circ}$ off-nadir position with eight spectra per plot.

To derive RGB-imagery based vegetation indices ( $\mathrm{VI}_{\mathrm{RGB}}$ ) one flight campaign with an UAV was carried out around noon. The multirotor UAV (MK Oktokopter XL; MicroKopter, Germany) was equipped with a Sony Alpha 6000 mounted on a gimbal. Images were acquired in about $50 \mathrm{~m}$ above ground level following the terrain with fixed aperture and whitebalance. Lighting conditions were stable during the flight. 18 ground control points (GCPs) were evenly distributed in and outside of the field and measured with a highly accurate RTK-DGPS (Topcon HiperPro 5). Additionally, six reference panels in different shades of grey and near lambertian properties were laid out for radiometric calibration of the orthomosaic using the Empirical Line Method (ELM, Smith \& Milton 1999). The reference panels were measured with an ASD FieldSpec3 (Analytical Spectral Devices, Boulder, USA) with a spectral range of $350-2000 \mathrm{~nm}$.

\subsection{Processing}

The image data was processed using the structure-from-motion software Agisoft Photoscan v1.3 to derive an orthomosaic of the study area with $7 \mathrm{~mm}$ spatial resolution.

The orthomosaic was calibrated per band to estimated surface reflectance using the Empirical Line Method. The ELM is a simple and direct approach to calibrate digital numbers (DN) of images to approximated units of surface reflectance. The relationship between at-sensor radiance and at-surface reflectance is estimated by measuring spectrally stable reference targets and comparing these measurements with the respective DNs in the image to derive a prediction equation for each image band. The derived prediction equations, which account for changes in illumination and atmospheric effects, are applied band wise to obtain images in units of estimated surface reflectance (Smith \& Milton, 1999, Karpouzli \& Malthus 2003).

The following RGB-based vegetation indices (see Table 1) were computed in ArcGIS v10.3 on a pixel basis from the calibrated orthomosaic: Red-Green-Blue Vegetation Index (RGBVI), Greean Leaf Index (GLI), Visible Atmospherically Resistant Index (VARI), and Normalized Green Red Difference Index
(NGRDI). The RGB-based indices were averaged over each plot with the tool Zonal Statistics as Table in ArcGIS.

From the N-Sensor measurements the Normalized Difference Vegetation Index (NDVI $\left.\mathrm{NIR}_{\text {, RED }}\right)$, an optimized NDVI (NDVI ${ }_{800,750)}$ and an optimized two band simple ratio index (SR810,750) (see Gnyp et al. 2015) were calculated per plot.

\begin{tabular}{l|c|l} 
VI Name & Equation & Reference \\
\hline RGBVI & $\left(\mathrm{R}_{\mathrm{G}} * \mathrm{R}_{\mathrm{G}}\right)-\left(\mathrm{R}_{\mathrm{R}} * \mathrm{R}_{\mathrm{B}}\right) /$ & Bendig et al. 2015 \\
& $\left(\mathrm{R}_{\mathrm{G}} * \mathrm{R}_{\mathrm{G}}\right)+\left(\mathrm{R}_{\mathrm{R}} * \mathrm{R}_{\mathrm{B}}\right)$ & \\
\hline GLI & $\left(2 * \mathrm{R}_{\mathrm{G}}-\mathrm{R}_{\mathrm{R}}-\mathrm{R}_{\mathrm{B}}\right) /$ & Louhaichi et al. \\
& $\left(2 * \mathrm{R}_{\mathrm{G}}+\mathrm{R}_{\mathrm{R}}+\mathrm{R}_{\mathrm{B}}\right)$ & 2001 \\
\hline VARI & $\left(\mathrm{R}_{\mathrm{G}}-\mathrm{R}_{\mathrm{R}}\right) /$ & Gitelson et al. \\
& $\left(\mathrm{R}_{\mathrm{G}}+\mathrm{R}_{\mathrm{R}}-\mathrm{R}_{\mathrm{B}}\right)$ & 2002 \\
\hline NGRDI & $\left(\mathrm{R}_{\mathrm{G}}-\mathrm{R}_{\mathrm{R}}\right) /$ & Tucker 1979 \\
& $\left(\mathrm{R}_{\mathrm{G}}+\mathrm{R}_{\mathrm{R}}\right)$ & \\
\hline NDVI & $\left(\mathrm{R}_{\mathrm{NIR}, \mathrm{RED}}-\mathrm{R}_{\mathrm{R}}\right) /$ & Rouse et al. 1974 \\
& $\left(\mathrm{R}_{\mathrm{NIR}}+\mathrm{R}_{\mathrm{R}}\right)$ & \\
\hline NDVI 800,750 & $\left(\mathrm{R}_{800}-\mathrm{R}_{750}\right) /$ & Gnyp et al. 2015 \\
& $\left(\mathrm{R}_{800}+\mathrm{R}_{750}\right)$ & \\
\hline SR810,750 & $\mathrm{R}_{810} / \mathrm{R}_{750}$ & Gnyp et al. 2015
\end{tabular}

Table 1. Applied Vegetation indices. $\mathrm{R}=$ reflectance $(\%)$, $\mathrm{R}_{\mathrm{R}}=$ red, $\mathrm{R}_{\mathrm{G}}=$ green, $\mathrm{R}_{\mathrm{B}}=$ blue, $\mathrm{R}_{\mathrm{NIR}}=$ near-infrared, $\mathrm{R}_{\mathrm{i}}=$ reflectance in narrow band region $\left(\mathrm{R}_{800}=800 \mathrm{~nm}\right)$.

\subsection{Statistical Analysis}

The aim of this study is to test the above mentioned VIs as predictor for DM yield in grassland. Therefore, linear regression models were calculated for each VI using R (R Development Core Team 2008). Two incomplete observations were removed. The dataset was split randomly into a calibration and validation subset (70/30). Regression models were calibrated by applying 10-fold cross-validation with five repetitions ( $\mathrm{R}$ caret-Package) on the calibration subset. The final regression model for each VI was tested on the remaining validation subset by linear correlation between observed and predicted $\mathrm{DM}$ yield $\mathrm{t} \mathrm{ha}^{-1}$. Coefficient of determination $\left(\mathrm{R}^{2}\right)$, standard error (SE), and the root mean squared error (RMSE) were calculated as performance measures of the regression models.

\section{RESULTS}

Figure 2 displays the dry matter yield $\left(\mathrm{t} \mathrm{ha}^{-1}\right)$ averaged over all replicates per treatment. Response of biomass accumulation to fertilizer input is clearly visible. No outliers are detected.

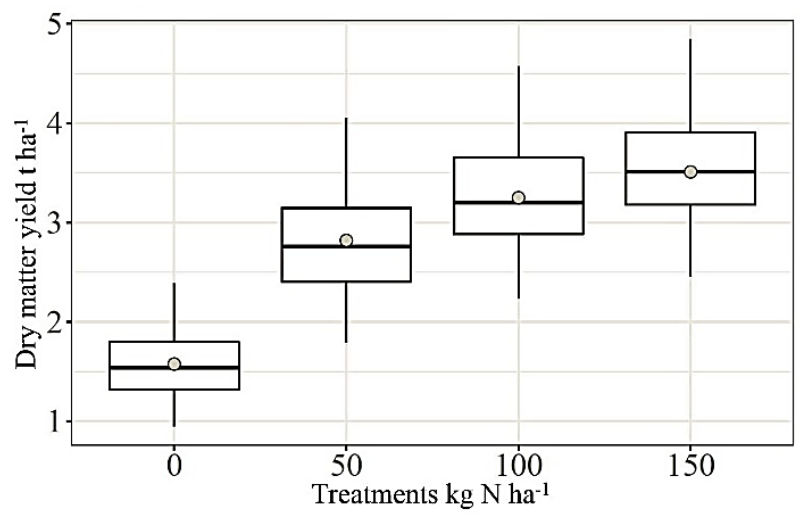

Fig. 2. Dry matter yield $\left(\mathrm{t} \mathrm{ha}^{-1}\right)$ per treatment. Point in box represents mean of dry matter yield $\left(\mathrm{t} \mathrm{ha}^{-1}\right)$. 


\subsection{Dry matter yield model calibration}

In Table 2 the regression models of the calibration subsets are listed for each VI.

\begin{tabular}{l|l|l|l|l} 
Estimator & Model equation & $\mathbf{R}^{\mathbf{2}}$ & $\mathbf{S E}$ & $\mathbf{n}$ \\
\hline RGBVI & $\mathrm{y}=-1.1 \mathrm{x}+3.534^{*}$ & 0.00 & 6.02 & 109 \\
\hline GLI & $\mathrm{y}=36.897 \mathrm{x}-10.305$ & 0.33 & 5.04 & 109 \\
\hline VARI & $\mathrm{y}=16.9789 \mathrm{x}-1.4906$ & 0.57 & 1.42 & 109 \\
\hline NGRDI & $\mathrm{y}=22.4527 \mathrm{x}-1.8501$ & 0.56 & 1.93 & 109 \\
\hline NDVI $_{\text {NIR, }}$, & $\mathrm{y}=34.336 \mathrm{x}-26.258$ & 0.65 & 2.45 & 109 \\
\hline NDVI $_{\mathbf{8 0 0}, \mathbf{7 5 0}}$ & $\mathrm{y}=83.6967 \mathrm{x}-1.2948$ & 0.65 & 5.85 & 109 \\
\hline SR810,750 $_{\mathbf{8 5 0}}$ & $\mathrm{y}=37.565 \mathrm{x}-38.834$ & 0.64 & 2.73 & 109
\end{tabular}

Table 2. Regression models of the calibration dataset.

$* P>0.5$, all other $P<0.005$

The regression model of the RGBVI was not significant and therefore left out of the model validation.

\subsection{Dry matter yield model validation}

The regression models derived from the calibration subset are applied to the validation subset to evaluate model performance.

\begin{tabular}{l|l|l|l|l} 
Estimator & Model equation & $\mathbf{R}^{2}$ & RMSE & $\mathbf{n}$ \\
\hline GLI & $\mathrm{y}=0.9878 \mathrm{x}+0.0798$ & 0.36 & 0.74 & 45 \\
\hline VARI & $\mathrm{y}=1.0719 \mathrm{x}-0.1649$ & 0.63 & 0.57 & 45 \\
\hline NGRDI & $\mathrm{y}=1.0693 \mathrm{x}-0.1528$ & 0.62 & 0.58 & 45 \\
\hline NDVI $_{\text {NIR, RED }}$ & $\mathrm{y}=0.975 \mathrm{x}+0.0501$ & 0.62 & 0.58 & 45 \\
\hline NDVI $_{800,750}$ & $\mathrm{y}=1.1045 \mathrm{x}-0.1664$ & 0.65 & 0.57 & 45 \\
\hline SR810,750 $_{\mathbf{8} 0}$ & $\mathrm{y}=1.0861 \mathrm{x}-0.1111$ & 0.63 & 0.58 & 45
\end{tabular}

Table 3. Regression models of the validation dataset.

$$
P<0.005
$$

Figure 3 a-c displays the validation results of three RGB-based VIs calculated from the orthomosaic.

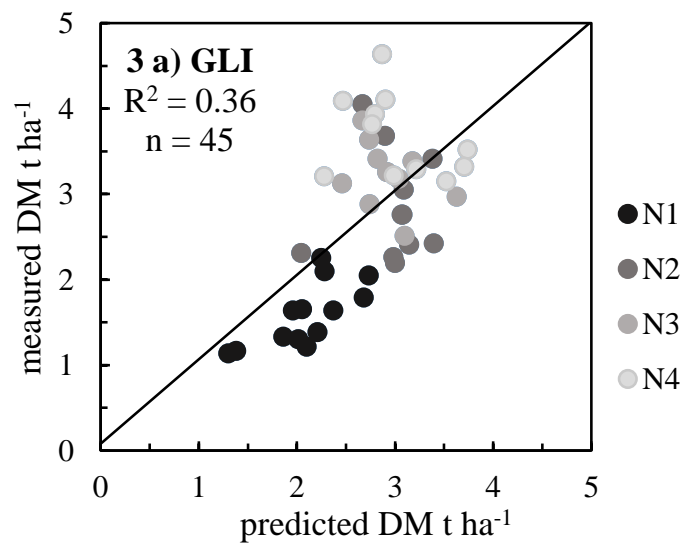

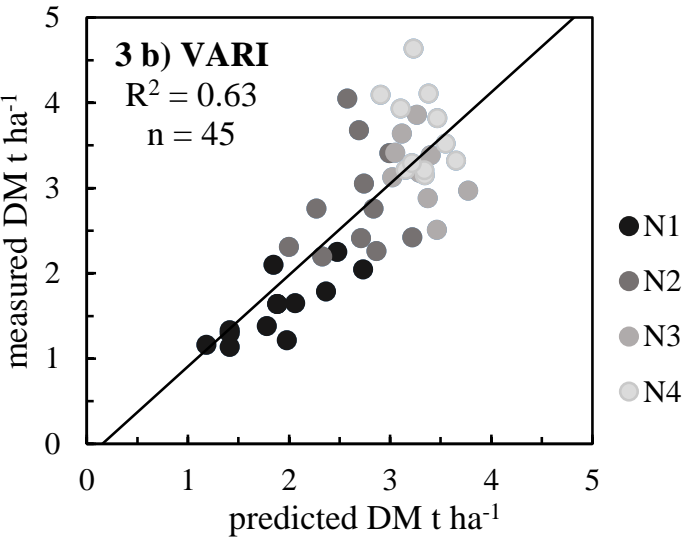

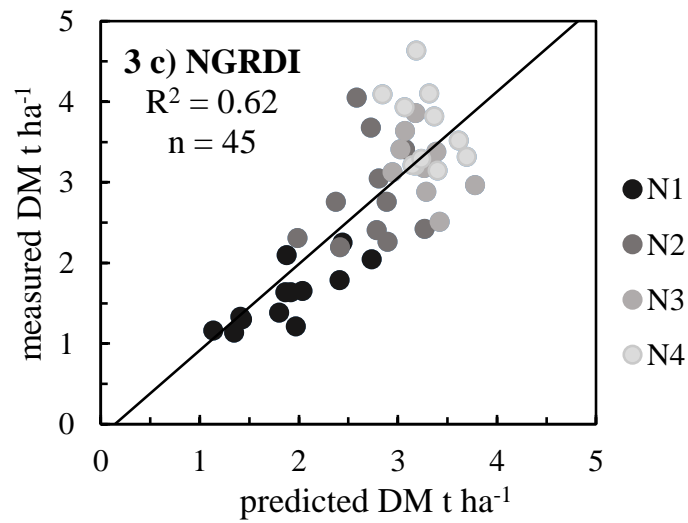

Figure 3 a-c. Cross-validation results for predicted and measured DM t ha ${ }^{-1}$ from validation subset of VIs derived from the orthomosaic.

N1: $0 \mathrm{~kg} \mathrm{~N}^{-1}, \mathrm{~N} 2: 50 \mathrm{~kg} \mathrm{~N}^{-1}$,

N3: $100 \mathrm{~kg} \mathrm{~N} \mathrm{ha}^{-1}, \mathrm{~N} 4: 150 \mathrm{~kg} \mathrm{~N} \mathrm{ha}^{-1}$.

The GLI performs least of the remaining $\mathrm{VI}_{\mathrm{RGB}}\left(\mathrm{R}^{2}=0.36\right)$. The VARI and NGRDI perform similarly well with an $\mathrm{R}^{2}$ of 0.63 and 0.62 respectively. All $\mathrm{VI}_{\mathrm{RGB}}$ show a saturation effect with respect to higher biomass levels (higher fertilizer treatments) and tend to underestimate the actual dry matter yield.

Figure 4 a-c shows the validation results of the VIs computed from the N-Sensor measurements. The optimized narrowband NDVI ${ }_{800,750}$ performs best with an $\mathrm{R}^{2}$ of 0.65 . The NDVI NIR,RED and the $\mathrm{SR}_{810,750}$ perform almost equally well.

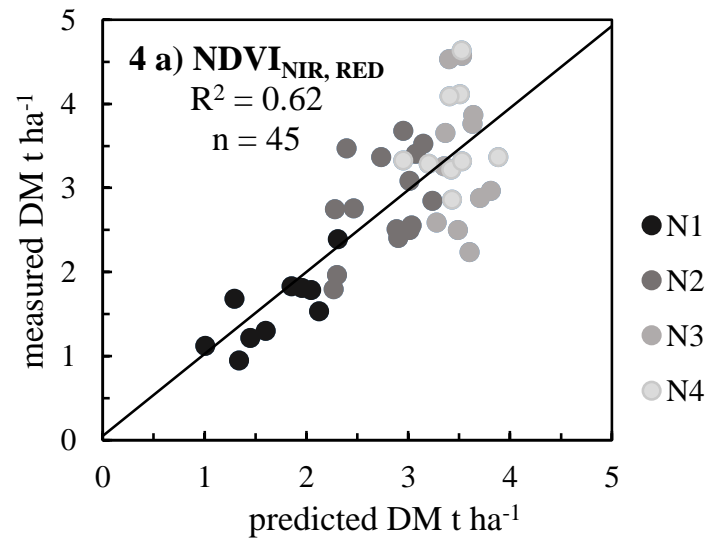



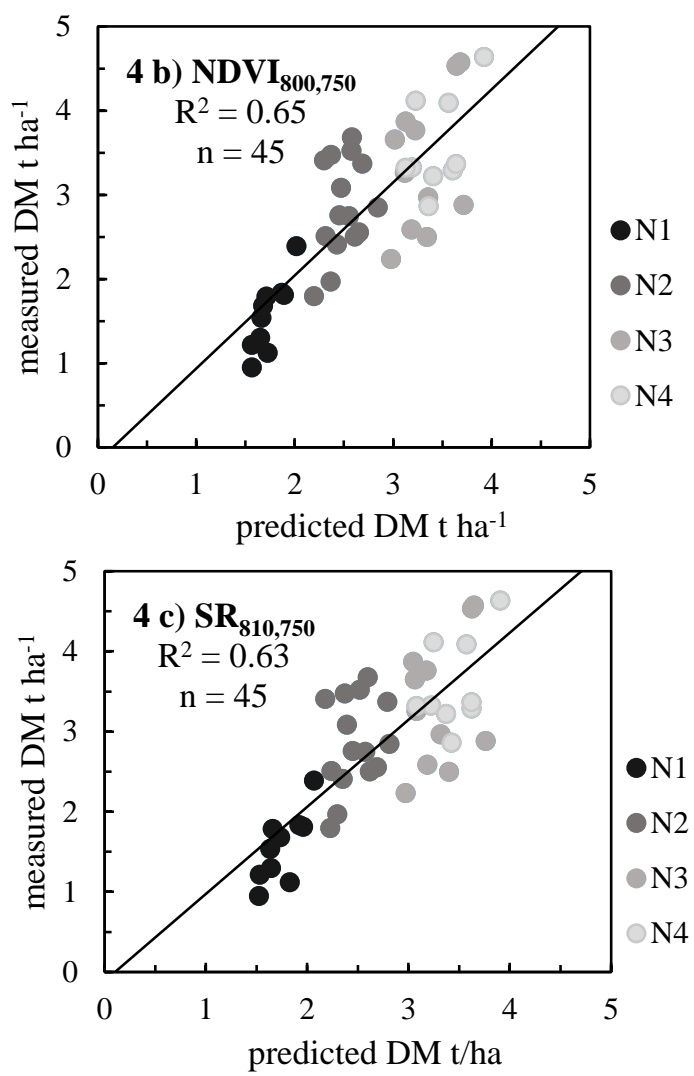

Figure 4 a-c. Cross-validation results for predicted and measured DM t ha ${ }^{-1}$ from validation subset of VIs derived from the Yara N-Sensor measurements. N1: $0 \mathrm{~kg} \mathrm{~N} \mathrm{ha}^{-1}, \mathrm{~N} 2: 50 \mathrm{~kg} \mathrm{~N} \mathrm{ha}^{-1}$, N3: $100 \mathrm{~kg} \mathrm{~N} \mathrm{ha}^{-1}, \mathrm{~N} 4: 150 \mathrm{~kg} \mathrm{~N} \mathrm{ha}^{-1}$.

For the optimized indices there is only a small saturation effect visible with higher biomass yield in comparison with the broadband $\mathrm{NDVI}_{\mathrm{NIR}, \mathrm{RED}}$ and the $\mathrm{VI}_{\mathrm{RGB}}$.

\section{DISCUSSION AND CONCLUSION}

The primary aim of this study is to evaluate the RGB-image based vegetation indices to predict dry matter forage yield and compare their performance to indices from the visible to nearinfrared spectrum on an experimental grassland field.

Using six reference targets for calibrating the orthomosaic to estimated surface reflectance by the Empirical Line Method minimizes errors in computing the prediction equation per band. This is especially important for multitemporal studies of vegetation parameters (Smith \& Milton 1999, Wang et al 2015). Surprisingly, the RGBVI, which performs moderate to well in other studies (Bendig et al., 2015; Bareth et al., 2016, Possoch et al. 2016) shows no correlation to the observed dry matter yield. The GLI performs also weak as an estimator of biomass. Both VIs incorporate the blue band in their equation, which might influence the result for certain grass species in different growing stages and N-supplies. This needs to be further investigated.

The VARI and NGRDI perform similarly to the Yara N-Sensor derived indices, but display stronger saturation effects. Motohka et al. (2010) state that application of VIs based on the visible spectrum are limited to certain growth stages.

It is important to note, that the Yara N-Sensor is not optimized for biomass or yield prediction but for $\mathrm{N}$-uptake. However, the derived VIs are suitable to estimate biomass as shown in Portz et al. (2017).
For biomass prediction Jannoura et al. (2015) showed a significant and positive correlation of NGRDI and aboveground biomass for oats and peas. Hunt et al. (2005) observed a linear correlation of NGRDI with alfalfa, corn, and soy biomass, but also observed saturation effects of the predictor variable for higher biomass yields.

The overall performance of the VIs was probably affected by slight lodging in plots with higher $\mathrm{N}$ applications. Here a differentiation of lodging and non-lodging plots would be beneficial.

Due to the field size the VISRGB were calculated from the orthomosaic and not from an overview image covering the whole field as discussed by Bendig et al. (2015) and Rasmussen et al. (2016). The latter can minimize effects of changing incident light but was not feasible due to the slope and size of the experimental field.

Furthermore, the radiometric response of the camera bands of the Sony Alpha 6000 is unknown and should be measured with a monochromatic light source as recommended by Hunt et al. (2005).

The performance of NGRDI and VARI in comparison with the $\mathrm{N}$-Sensor derived indices indicate a promising approach for biomass monitoring in grassland with a high spatial and temporal resolution.

Further investigations should be directed to evaluate RGB-based VIs for multiple cuts per test site and validate the results with independent datasets. Furthermore, the combination of VIs with structural parameters such as sward height from crop surface models to predict biomass or dry matter yield in grasslands should be the next step for investigation (Marshall \& Thenkabail, 2015; Bendig et al. 2015; Geipel et al. 2014).

\section{REFERENCES}

Bareth, G., Bolten, A., Gnyp, M. L., Reusch, S., Jasper, J. 2016. Comparison of uncalibrated RGBVI with spectrometer-based NDVI derived from UAV sensing systems on field scale. The International Archives of the Photogrammetry, Remote Sensing and Spatial Information Sciences, Volume XLI-B8, 2016 XXIII ISPRS Congress, 12-19 July 2016, Prague, Czech Republic, pp. 837-843.

Bendig, J., Yu, K., Aasen, H., Bolten, A., Bennertz, S., Broscheit, J., Gnyp, M.L., and Bareth, G., 2015. Combining UAV-based plant height from crop surface models, visible, and near infrared vegetation indices for biomass monitoring in barley. International Journal of Applied Earth Observation and Geoinformation, 39, pp. 79-87.

Ellis, E., Ramankutty, N., 2008. Putting people on the map, anthropogenic biomes of the world. Frontiers in Ecology and Environment, 6, pp. 439-447.

Geipel, J., Link, J., Claupein, W., 2014. Combined Spectral and Spatial Modeling of Corn Yield Based on Aerial Images and Crop Surface Models Acquired with an Unmanned Aircraft System. Remote Sensing, 6(11), pp. 10335-10355.

Gnyp, M.L., Panitzki, M., Reusch, S., 2015. Proximal nitrogen sensing by off-nadir and nadir measurements in winter wheat canopy. In: Stafford, J.V. (Ed.) Proceedings of the European Conference on Precision Agriculture 2015, Tel Aviv. Pp. 43-50.

Hunt, E.R., Cavigelli, M., Daughtry, C., McMurtrey, J., Walthall, C. 2005. Evaluation of Digital Photography from Model Aircraft 
for Remote Sensing of Crop Biomass and Nitrogen Status. Precision Agriculture, 6, pp. 359-378.

Hunt, E.R., Doraiswamy, P., McMurtrey, J., Daughtry, C., Perry, E., 2013. A visible band index for remote sensing leaf chlorophyll content at the canopy scale. International Journal of Applied Earth Observation and Geoinformation. 21, pp. 103112.

Jannoura, R., Brinkmann, K., Uteau, D., Bruns, C., Joergensen, R.G., 2015. Monitoring of crop biomass using true colour aerial photographs taken from from a remote controlled hexacopter. Biosystems Engineering, 129, pp.341-351.

Karpouzli, E., Malthus, T. 2003. The empirical line method for the atmospheric correction of IKONOS imagery. International Journal of Remote Sensing, 24 (5), pp. 1143-1150.

Marshall, M., Thenkabail, P., 2015. Developing in situ NonDestructive Estimates of Crop Biomass to Adress Issues of Scale in Remote Sensing. Remote Sensing, 7, pp. 808-835.

Motohka, T., Nasahara, K.N., Oguma, H., Tsuchida, S., 2010. Applicability of Green-Red Vegetation Index for Remote Sensing of Vegetation Phenology. Remote Sensing, 2, pp. 23692387.

Portz, G., Gnyp, M., Jasper, J., 2017. Capability of crop canopy sensing to predict crop parameters of cut grass swards aiming at early season variable rate nitrogen top dressings. Advances in Animal Biosciences: Precision Agriculture (ECPA), 8 (2), pp. 792-795.

Possoch, M., Bieker, S., Hoffmeister, D., Bolten, A., Schellberg, J., Bareth, G., 2016. Multi-temporal crop surface models combined with the RGB vegetation index from UAV-based images for forage monitoring in grassland. Volume XLI-B1, 2016 XXIII ISPRS Congress, 12-19 July 2016, Prague, Czech Republic, pp. 991-998.

R Development Core Team, 2008. R: A language and environment for statistical computing. $\mathrm{R}$ Foundation for Statistical Computing, Vienna, Austria. ISBN 3-900051-07-0, URL http://www.R-project.org.

Rasmussen, J., Ntakos, G., Nielsen, J., Svensgaard, J., Poulsen, R., Christensen, S., 2016 Are vegetation indices derived from consumer-grade cameras mounted on UAVs sufficiently reliable for assessing experimental plots? European Journal of Agronomy, 74, pp. 75-92.

Rouse, J., Jr., Haas, R., Schell, J., Deering, D. 1974. Monitoring vegetation systems in the Great Plains with ERTS. NASA Special Publication, 351, pp. 309-317.

Schellberg, J., Verbruggen, E., 2014. Frontiers and perspectives on research strategies in grassland technology. Crop \& Pasture Science, 65, pp. 508-523.

Smith, G., Milton, E. 1999. The use of the empirical line method to calibrate remotely sensed data to reflectance. International Journal of Remote Sensing, 20 (13), pp. 2653-2662. 